\title{
GAMBARAN TINGKAT PENGETAHUAN IBU TENTANG PEMBERIAN MAKANAN BERGIZI PADA BALITA DI WILAYAH POSYANDU TULIP RT 04 RW 07 DESA PETIKEN DRIYOREJO - GRESIK
}

\author{
Dianita Primihastuti \\ Email: nita63186@gmail.com
}

\begin{abstract}
ABSTRAK
Gizi seimbang dibutuhkan oleh setiap tubuh manusia, terutama pada balita. Gizi seimbang dengan kualitas dan kuantitas yang tepat sangat diperlukan oleh balita yang masih dalam usia pertumbuhan dan perkembangan. Berdasarkan pengamatan peneliti didapatkan ibu yang memberikan makanan sesuai keinginan balita tanpa memperhatikan makanan tersebut bergizi atau tidak. Pemenuhan kebutuhan gizi secara tepat pada balita perlu diperhatikan karena menciptakan sttus gizi yang baik pada balita tentunya sangat berguna bagi kehidupan di masa depan. Tujuan penelitian ini untuk memperoleh gambaran tingkat pengetahuan ibu tentang pemberian makanan bergizi pada balita di wilayah Posyandu Tulip RT 04 RW 07 Desa Petiken Driyorejo Gresik. Penelitian ini menggunakan desain deskriptif dengan metode total sampling. Populasi dalam penelitian ini yaitu semua ibu yang mempunyai anak balita (27 responden). Pengumpulan data dilakukan dengan kuesioner kemudian diolah secara manual meliputi menganalisa hasil, memberi kode, memasukkan data ke tabel distribusi frekuensi. Hasil penelitian ini menggambarkan tingkat pengetahuan ibu tentang pemberian makanan bergizi pada balita, yaitu: pengetahuan baik $70 \%$, pengetahuan cukup $11 \%$, dan pengetahuan kurang $19 \%$. Jadi tingkat pengetahuan ibu tentang pemberian makanan bergizi pada balita sudah baik. Dengan pengetahuan yang baik seharusnya ibu dapat memberikan makanan yang bergizi kepada anak agar pertumbuhan dan perkembangan balita menjadi optimal.
\end{abstract}

Kata Kunci: Tingkat pengetahuan, makanan bergizi pada balita, ibu

\begin{abstract}
Balanced Nutrition is needed by every human body, especially toddlers. Toddlers who are still in the age of growth and development is in need of balanced nutrition with the right quality and quantity. Based on the observations of researchers found that mothers feeding as toddlers wish without regard to food is nutritious or not. Nutritional needs appropriately in toddlers need to be considered as creating a good nutritional status among toddlers is certainly very useful for future life. The purpose of this study was to obtain a level of knowledge of mothers about nutrition feeding for her toddlers in the Posyandu Tulip RT 04 RW 07 Desa Petiken Driyorejo Gresik. This study uses a descriptive design with a total sampling methods. The population is all mothers who have toddler, it was 27 respondents.Data was collected through questionnaires then processed manually include analyzing results, encodes, entering data into a frequency distribution table. Results of this study illustrate the level of mothers' knowledge of nutrition feeding for toddlers, that is: good knowledge is $70 \%, 11 \%$ is sufficient knowledge, and less knowledge is $19 \%$. Thus, the mother's level of knowledge regarding the provision of nutritious food to children are good. With a good knowledge, mother should be able to provide nutritious food to her toddlers so that the growth and development of toddler being optimal.
\end{abstract}

Keywords: Level of Knowdledge, Nutrious Foods for Toddlers, Mothers 


\section{PENDAHULUAN}

Gizi merupakan bagian penting dari proses kehidupan manusia. Gizi yang seimbang dibutuhkan oleh setiap tubuh manusia, terutama pada balita. Gizi seimbang dengan Kualitas serta kuantitas yang tepat sangat dibutuhkan oleh balita dalam usia pertumbuhan dan perkembangan. Pemenuhan kebutuhan gizi secara tepat pada balita, dapat menciptakan status gizi yang baik bagi balita tentunya sebagai generasi bangsa di masa mendatang. Hal yang harus diperhatikan dalam pemenuhan kebutuhan gizi balita adalah pemberian makanan. Sebagian besar kehidupan balita masih bergantung pada ibu khususnya dalam hal pemberian makanan, maka mewajibkan ibu sebagai orang terdekat balita harus memiliki pengetahuan yang baik tentang gizi balita karena hal tersebut sangat menentukan status gizi balita.

Kemampuan seseorang dalam membuat menu yang baik untuk dikonsumsi akan tercipta jika seseorang memiliki pengetahuan gizi yang baik pula. Semakin luas pengetahuan gizi seseorang maka akan semakin baik dalam memperhitungkan jenis dan jumlah makanan yang diperoleh untuk dikonsumsi (Sediaoetama, 2000). Namun pada kenyataannya, masih terdapat ibu yang pengetahuannya masih kurang tentang pemberian makanan bergizi pada balita. Hal ini ditunjukkan dengan cara ibu dalam memberikan nutrisi pada balita. Dalam kehidupan sehari - hari, pada umumnya ibu memberikan makanan seperti nasi dengan kuah bakso, nasi dengan mie, nasi dengan kecap dan krupuk saja, dan nasi dengan makanan ringan (snack seperti pilus). Ibu-ibu pada umumnya juga cenderung memilih pilihan makanan yang lebih disukai balita, tanpa memperhatikan apakah makanan tersebut sehat dan mengandung cukup gizi, yang terpenting bagi ibu balita mau makan. Tentunya kebutuhan akan gizi yang tidak sesuai dapat menyebabkan gizi kurang pada balita.

Menurut data Dinas Kesehatan Provinsi Jawa Timur pada tahun 2011 di
Jawa Timur terjadi 6.499 kematian balita dengan AKABA 10,81 per 1.000 kelahiran hidup. Sedangkan dari hasil laporan Kejadian Luar Biasa (KLB) gizi buruk tahun 2011 di Jawa Timur terdapat 6925 anak balita yang menderita gizi buruk. Untuk Kabupaten Gresik angka kematian balita mencapai $25,40 \%$, dan penyebab gizi buruk ternyata tidak disebabkan oleh faktor kemiskinan, namun penyebab utama yaitu $40,7 \%$ pola asuh anak yang salah dimana balita kurang mendapat asupan makanan berkualitas dan bergizi. Dari studi awal yang dilakukan di Posyandu Tulip RT 04 RW 07 Desa Petiken Driyorejo Gresik, terhadap 10 responden yang merupakan ibu balita, ditemukan $6 \mathrm{ibu}$ mengatakan selalu memberikan makanan sesuai dengan keinginan anaknya tanpa memperhatikan makanan tersebut bergizi atau tidak daripada anak tidak mau makan dan menangis, dan 4 ibu mengatakan bahwa anaknya selalu diberikan lauk dan sayur berbeda setiap harinya, karena selain mencegah supaya anak tidak bosan, menurut ibu dengan memberikan lauk dan sayur yang bervariasi setiap hari maka gizi pada anaknya akan tercukupi dan ibu juga mengatakan bahwa makanan yang bervariasi adalah makanan yang bergizi.

Gizi pada balita masih menjadi masalah di Negara Indonesia. Hal ini umumnya terjadi karena kurangnya tingkat pengetahuan ibu tentang pemberian makanan bergizi pada balita. Kurangnya tingkat pengetahuan ibu disebabkan oleh antara lain tingkat pendidikan ibu yang masih rendah, intensitas untuk datang ke posyandu atau fasilitas kesehatan lain yang kurang, serta kurangnya keinginan ibu untuk mencari informasi tentang pentingnya pemberian makanan bergizi. Dari hasil pengamatan yang telah dilakukan peneliti terdapat adanya dampak pada balita terhadap hal tersebut yaitu balita kurang bergerak aktif layaknya balita seusianya, rambut kemerahan seperti cacingan, kelopak mata yang tampak kehitaman, juga terdapat balita yang sering sakit. Tentunya jika tidak segera diatasi akan 
mengganggu pertumbuhan dan perkembangan balita.

Untuk mencegah semakin bertambahnya balita yang mengalami masalah gizi, dapat dilakukan upaya untuk meningkatkan pengetahuan ibu dengan beberapa cara seperti mengikuti penyuluhan yang dilakukan oleh tenaga kesehatan tentang makanan bergizi untuk balita, memberikan motivasi pada ibu untuk lebih memperhatikan gizi dalam pemberian makanan pada balita misalnya dengan membuat menu makanan balita yang kreatif dan mengandung gizi seimbang, memberikan dorongan untuk mencari informasi tentang pentingnya gizi melalui televisi, internet, radio, koran, majalah.

\section{BAHAN DAN METODE}

Metode penelitian merupakan cara memahami sesuatu melalui penyelidikan melalui bukti yang muncul sehubungan dengan masalah tersebut, dilakukan secara hati-hati sehingga diperoleh pemecahan (Notoatmodjo, 2008). "deskriptif" yang bertujuan untuk mendapatkan gambaran tingkat pengetahuan ibu tentang pemberian makanan bergizi pada balita di wilayah Posyandu Tulip RT 04 RW 07 Desa Petiken Driyorejo Gresik.

Populasi dalam penelitian ini adalah Semua ibu yang mempunyai anak balita di wilayah Posyandu Tulip RT 04 RW 07 Desa Petiken Driyorejo Gresik $(\mathrm{N}=27)$. Teknik sampling dalam penelitian ini menggunakan total sampling, yaitu teknik bila semua anggota populasi digunakan sebagai sampel (Setiadi, 2007).

Pada penelitian ini kuisioner digunakan dalam tehnik pengumpulan data dalam penelitian ini menggunakan kuesioner. kuesioner pada responden yang diteliti tingkat pengetahuannya yaitu pada ibu yang mempunyai anak balita di Posyandu
Tulip RT 04 RW 07 di Desa Petiken Driyorejo Gresik.

\section{HASIL}

\section{DATA UMUM}

Data umum ini menggambarkan tentang karateristik responden berdasarkan usia, pendidikan dan pekerjaan.

\subsection{Karakteristik Responden Berdasarkan} Usia.

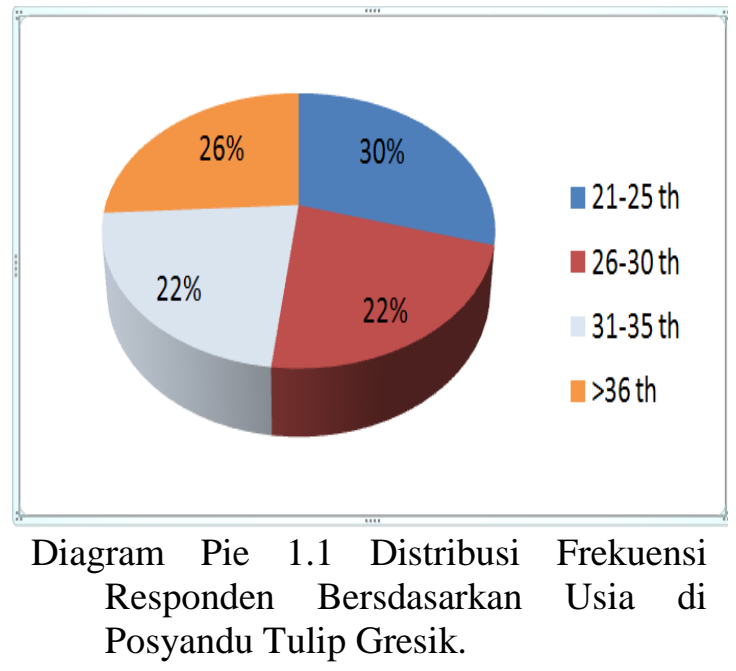

Berdasarkan Diagram Pie 1.1 di atas menunjukkan bahwa ibu yang menjadi responden hampir setengahnya berusia 21-25 tahun, yaitu sebanyak 8 responden (30\%).

1.2 Karakteristik Responden Berdasarkan Tingkat Pendidikan.

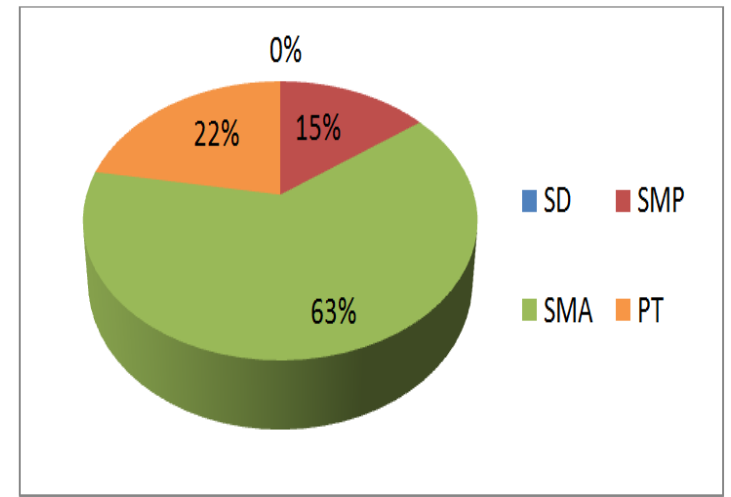

Diagram Pie 1.2 Distribusi Frekuensi Responden Bedasarkan Pendidikan di Posyandu Tulip Gresik.

Berdasarkan Diagram Pie 1.2 di atas menunjukkan bahwa sebagian besar 
responden memiliki tingkat pendidikan SMA, yaitu sebanyak 17 responden (63\%).

\subsection{Karakteristik responden berdasarkan pekerjaan.}

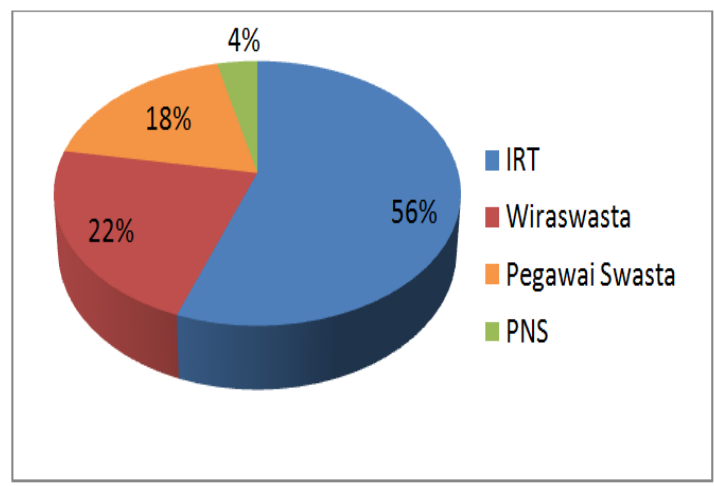

Diagram Pie 1.3 Distribusi Frekuensi Responden Bedasarkan Pekerjaan di Posyandu Tulip Gresik.

Berdasarkan Diagram Pie 1.3 di atas menunjukkan bahwa sebagian besar responden memiliki pekerjaan sebagai Ibu Rumah Tangga (IRT), yaitu sebanyak 15 responden $(56 \%)$.

1.4 Karakteristik responden berdasarkan penghasilan.

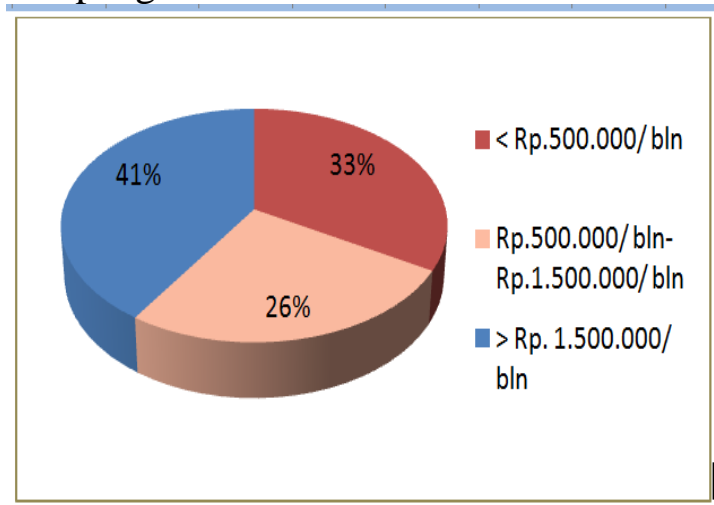

Diagram Pie 1.4 Distribusi Frekuensi Responden Bedasarkan Penghasilan di Posyandu Tulip Gresik.

Berdasarkan Diagram Pie 1.4 di atas menunjukkan bahwa hampir setengah dari responden memiliki penghasilan > Rp. 1.500.000/ bulan, yaitu sebesar 11 responden $(41 \%)$.

\section{DATA KHUSUS}

Data khusus ini menggunakan tingkat pengetahuan ibu tentang Pemberian Makanan Bergizi pada Balita di Posyandu Tulip Gresik.

Tabel 2.1 Tingkat Pengetahuan Ibu tentang Pemberian Makanan Bergizi pada Balita di Posyandu Tulip.

\begin{tabular}{cc}
\hline Tingkat Pengetahuan & Prosentase \\
\hline Baik & $70 \%$ \\
\hline Cukup & $11 \%$ \\
\hline Kurang & $19 \%$ \\
\hline
\end{tabular}

Berdasarkan Tabel 2.1 di atas menunjukkan hasil analisis frekuensi jawaban responden berdasarkan kriteria tingkat pengetahuan yang dimiliki responden terhadap pemberian makanan bergizi pada balita. Analisis frekuensi jawaban responden menunjukkan bahwa secara garis besar responden telah memiliki tingkat pengetahuan yang baik terhadap pemberian makanan bergizi pada balita yaitu sebanyak 19 responden (70\%).

\section{PEMBAHASAN}

Pada pembahasan ini akan diuraikan hasil penelitian mengenai gambaran tingkat pengetahuan ibu tentang pemberian makanan bergizi pada balita di wilayah Posyandu Tulip RT 04 RW 07 Desa Petiken Driyorejo Gresik. Diagram 1.1 menunjukkan bahwa ibu-ibu di wilayah Posyandu Tulip RT 04 RW 07 Desa Petiken Driyorejo Gresik hampir setengahnya berusia 21-25 tahun, yaitu sebanyak 8 responden (30\%). Menurut Notoatmodjo (2007), daya tanggap dan pola piker seseorang dipengaruhi oleh usia sehingga pengetahuan semakin membaik. Apabila dikaitkan dengan diagram 1.1 maka tidak terdapat kesenjangan antara kasus nyata dan teori bahwa ini tergolong usia dewasa muda dan produktif sehingga keinginan untuk mencari informasi lebih tinggi dan mereka cenderung aktif dalam mencari informasi tentang pemberian makanan 
bergizi pada balita melalui kunjungan ke posyandu dan tenaga kesehatan.

Diagram 1.2 menunjukkan bahwa sebagian besar responden memiliki tingkat pendidikan SMA, yaitu sebanyak 17 responden (63\%). Menurut Notoatmodjo (2003), menyatakan pengetahuan yang baik dipengaruhi oleh tingginya tingkat pendidikan seseorang. Hal ini sesuai dengan pendapat Notoatmodjo bahwa sebagian besar ibu berpendidikan SMA. Oleh karena itu tingkat pendidikan yang baik akan mempengaruhi kematangan serta kemampuan mereka dalam menerima dan mencari informasi, dan berpengaruh dalam perilaku responden untuk memberikan makanan bergizi pada balitanya.

Diagram 1.3 menunjukkan bahwa sebagian besar responden adalah Ibu Rumah Tangga (IRT), yaitu sebanyak 15 responden (56\%). Apabila dikaitkan dengan tabel 2.1 maka tidak terdapat kesenjangan antara kasus nyata dan teori bahwa ibu rumah tangga cenderung beraktivitas di dalam rumah, oleh karena itu ibu rumah tangga memiliki waktu luang yang lebih banyak dibandingkan dengan ibu-ibu lain yang bekerja. Waktu luang yang lebih banyak dapat memberikan lebih banyak kesempatan kepada mereka untuk mencari informasi, melalui media massa, media cetak, kunjungan ke posyandu, diskusi dengan ibu-ibu lainnya. Waktu luang yang banyak akan memberikan mereka kesempatan lebih banyak untuk aktif mengumpulkan informasi dan bertukar pikiran.

Diagram 1.4 menunjukkan bahwa hampir setengah dari responden memiliki penghasilan > Rp. 1.500 .000 per bulan, yaitu sebanyak 11 responden (41\%). Menurut Supriasa (2002), kebutuhan primer, sekunder serta kasih sayang yang diperoleh anak akan dipengaruhi dengan tingkat pendapatan keluarga. Hal ini sangat sesuai dengan teori, dimana tercukupinya kebutuhan primer dengan penghasilan yang diperoleh ibu sehingga terpenuhinya status gizi yang baik pada balita. Status gizi seseorang dipengaruhi oleh konsumsi pangan keluarga. Tentunya hal tersebut tidak lepas dari status ekonomi yang akan sangat mempengaruhi ibu dalam pemilihan bahan makanan. Semakin tercukupinya pendapatan dalam keluarga, maka akan semakin selektif mencari bahan makanan yang baik dan bervariasi sehingga anak balita mendapatkan makanan yang bergizi.

\section{SIMPULAN}

Berdasarkan hasil dari penelitian dengan judul "Gambaran Pengetahuan Ibu tentang Pemberian Makanan Bergizi pada Balita" dapat disimpulkan bahwa mayoritas responden berpengetahuan baik yaitu sebanyak 19 orang $(70 \%)$.

\section{SARAN}

Bagi Kader Posyandu atau Petugas Kesehatan yaitu diharapkan dapat Mempertahankan kegiatan-kegiatan posyandu yang sudah dilakukan selama ini serta menambah pemberian informasi dan wawasan kader atau petugas kesehatan melalui penyuluhan kesehatan tentang pemberian makanan bergizi pada balita dan mampu mengaplikasikan dalam kehidupan sehari-hari sehingga tidak terjadi masalah yang berkaitan dengan gizi.

Bagi Instansi Pendidikan, Semoga Karya Tulis Ilmiah ini dapat digunakan menjadi bahan referensi dan informasi bagi dosen maupun mahasiswa kebidanan tentang pemberian makanan bergizi pada balita sehingga para mahasiswa mampu untuk meningkatkan informasi pada masyarakat tentang pemberian makanan bergizi pada balita.

Bagi Peneliti Selanjutnya diharapkan penelitian ini dapat menjadi acuan bagi peneliti selanjutnya dalam mengembangkan penelitian serupa serta dalam penelitan selanjutnya diharapkan dapat mengkaji faktor-faktor apa saja yang mempengaruhi ibu dalam pemberian makanan bergizi pada balita atau hubungan tingkat pengetahuan tentang pemberian makanan bergizi pada balita dengan sikap ibu dalam pemberian makanan bergizi pada balita. 


\section{DAFTAR PUSTAKA}

Alimul, Aziz. 2012. Pengantar Ilmu Keperawatan Anak I. Jakarta: Salemba Medika

Almatsier, Sunita. 2005. Prinsip-prinsip Dasar Ilmu Gizi. Jakarta: Gramedia Pustaka Utama

Arikunto, S. 2006. Prosedur Penelitian Suatu Pendekatan Praktek. Jakarta: Rineka Cipta

Azwar, Saifuddin. 2011. Sikap Manusia Teori dan Pengukurannya. Yogyakarta: Pustaka Pelajar

Dinkes Provinsi Jatim. 2012. Profil Kesehatan Provinsi Jawa Timur Tahun 2011. http://dinkes.jatimprov.go.id diunduh tanggal 23 Februari 2013 jam 22.09 WIB.

Effendy. 2004. Dasar-dasar Keperawatan Kesehatan Masyarakat. Jakarta: EGC

Maryati. 2000. Menu Makanan dan Variasi Makanan Pada Balita. Jakarta: http://www.ejournal.unesa.ac.id diunduh tanggal 24 Februari 2013 jam 23.46 WIB

Lia, Amalia dan Mardiah. 2006. Makanan Tepat Untuk Balita. Jakarta: Kawan Pustaka

Luluk. 2005. Resiko Pemberian MPASI Terlalu Dini. http://wrmindonesia.org/content/vie w/647 diunduh tanggal 23 Mei 2013 jam 02.17 WIB

Nursalam. 2003. Konsep dan Penerapan Metodologi Ilmu Keperawatan Pedoman Skripsi, Tesis dan Instrumen Penelitian Keperawatan. Jakarta: Salemba Medika

Notoatmodjo, S. 2003. Metode Penelitian Kesehatan. Jakarta: Rineka Cipta

Notoatmodjo, S. 2007. Promosi Kesehatan dan Ilmu Perilaku. Jakarta: Rineka Cipta
Poerwodarminto, W.J.S. 2003. Kamus Umum Bahasa Indonesia. Jakarta: Balai Pustaka

Proverawati, Atikah. 2009. Buku Ajar Gizi untuk Kebidanan. Yogyakarta: Nuha Medika

Supriasa. 2002. Penilaian Status Gizi. Jakarta: EGC.

Sediaoetama, Achmad Djaeni. 2000. Ilmu Gizi untuk Mahasiswa dan Profesi Jilid I. Jakarta: Dian Rakyat

Setiadi. 2007. Konsep dan Penulisan Riset Keperawatan. Yogyakarta: Graha Ilmu

Soetjiningsih. 2001. Tumbuh Kembang Anak. Jakarta: EGC 